\title{
Evaluating the association between early-lactation lying behavior and hoof lesion development in lactating Jersey cows
}

\author{
B. O. Omontese, ${ }^{1,2} \odot$ R. S. Bisinotto, ${ }^{3} \odot$ and G. Cramer ${ }^{2 *}\left({ }^{\circ}\right.$ \\ ${ }^{1}$ Department of Food and Animal Sciences, Alabama A\&M University, Normal 35762 \\ ${ }^{2}$ Department of Veterinary Population Medicine, University of Minnesota, St. Paul 55108 \\ ${ }^{3}$ Department of Large Animal Clinical Sciences, University of Florida, Gainesville 32610
}

\begin{abstract}
Objectives were to evaluate the association between behavior and hoof lesions (HL) in lactating dairy cows. Jersey cows without any visible HL on all 4 legs were enrolled at $20 \pm 3 \mathrm{~d}$ in milk (DIM), examined for body condition score (BCS), and had an automatic activity monitor (AfiTag II, AfiMilk, Afikim, Israel) attached to their right hind leg. At $120 \pm 3$ DIM, activity monitors were removed and cows were re-examined for HL and BCS. Cows were classified according to HL status as either healthy or with HL at d 120. Because sole hemorrhage (SH) accounted for over $80 \%$ of $\mathrm{HL}$ on $\mathrm{d}$ 120, SH was reclassified according to the number of feet affected. Daily activity data (daily lying duration, lying bouts, lying bout duration, and number of steps) of 344 cows collected between d 20 and d 120 were analyzed using restricted maximum likelihood linear mixed models with an autoregressive covariance structure. Separate models were built to include specific activities, HL status at d 120, DIM, interaction between lesion status at d 120 and DIM, parity, season of calving, and BCS change from d 20 to d 120 as fixed effects. Cow was included in all models as random effect. Incidence of HL at d 120 was $58.4 \%(n=201$ out of 344$)$. Compared with healthy cows, cows with HL at d 120 had reduced daily lying duration $(-0.53 \mathrm{~h} ; 95 \% \mathrm{CI}:-0.78$ to -0.28 $\mathrm{h}$ ) in the early postpartum period. We found no evidence for a difference in number of lying bouts $(0.41 ; 95 \%$ CI: -0.76 to $1.59 ;)$, lying bout duration ( $-3.04 \mathrm{~min} ; 95 \%$ CI: -6.6 to 0.49$)$, and number of steps $(62.14 ; 95 \%$ CI: -89.62 to 213.91 ) between cows that remained healthy and those that developed HL. Compared with healthy cows, cows that developed SH in 1 or more feet had reduced daily lying duration in the early postpartum period. Irrespective of lesion status at d 120, daily lying duration and lying bout duration increased from $\mathrm{d}$
\end{abstract}

Received January 23, 2020.

Accepted July 12, 2020.

*Corresponding author: gcramer@umn.edu
20 to d 120, whereas lying bout number and number of steps decreased from d 20 to d 120 . We concluded that cows that developed HL had a reduced daily lying duration in the early postpartum period. Therefore, reduced daily lying duration should be considered a risk factor for HL development in lactating dairy cows. Key words: hoof lesion, lying duration, lying bout, number of steps

\section{INTRODUCTION}

Lameness is a painful condition mostly caused by hoof lesions (HL) and is indicative of reduced cow welfare (Huxley, 2013). Dairy producers often underestimate the prevalence of lameness in their herds (Espejo et al., 2006) because lameness detection is challenging. With increased dairy herd consolidation, time, finances, and labor are important limiting factors for lameness control activities (Leach et al., 2010). Therefore, growing need exists for tools that support early detection and management of lame cows. The specific cow behaviors lying duration, number of lying bouts, and feeding behavior have been shown to be vital indicators of cow welfare and health status, and could potentially be used in the prediction of ill health, including lameness (Weary et al., 2009; Norring et al., 2014). For example, lame cows can exhibit marked behavioral changes that distinguish them from nonlame cows (González et al., 2008; Ito et al., 2010; Norring et al., 2014).

In most US dairy herds, visual locomotion scoring, as described by Sprecher et al. (1997), is routinely recommended for lameness diagnosis and monitoring. However, routine early lameness detection via visual locomotion scoring is laborious and time-consuming. Alternatively, activity monitoring systems are increasingly being installed and could potentially be used to implement automated lameness detection strategies (Thomsen, 2009; Alsaaod et al., 2019). Activity monitoring systems provide a variety of objective data on cattle behaviors, including daily lying duration, number of lying bouts, lying bout duration, and number of steps. 
Use of automated activity monitoring systems to detect lameness and hoof lesions in lactating cows has been reported (Charlton et al., 2016; Sepúlveda-Varas et al., 2018). The majority of these studies used locomotion scoring for lameness diagnosis and did not consider the influence of specific HL or HL development. Monitoring behaviors of initially healthy cows (cows without any visible HL) before they develop HL will increase our understanding of changes in behavior patterns that occur during HL development and provide insight into specific cow behaviors that dairy personnel should consider in early lameness diagnosis. Investment in automated activity monitoring systems may improve cow welfare and dairy herd net profit (Kaniyamattam et al., 2020). Previous research has shown that changes in standing and lying behavior during the transition period may predispose cows to the development of HL (Proudfoot et al., 2010; Dippel et al., 2011). Although information about the relationship between behavior and lameness abounds in the literature (Ito et al., 2010; Solano et al., 2016), information about the association between specific behaviors and HL development is more limited, even though lameness is mostly caused by HL. Therefore, the aim of this study was to evaluate the association between behavior and HL in lactating Jersey cows. Our hypothesis is that, compared with healthy cows, cows that develop HL will show marked deviation in behavior. Specifically, we hypothesize that, compared with cows that remain healthy, cows that develop HL will have decreased lying duration and increased number of lying bouts and number of steps.

\section{MATERIALS AND METHODS}

\section{Farm and Management}

All experimental protocols were approved by the Institutional Animal Care and Use Committee of the University of Minnesota (St. Paul, MN; Protocol ID: 1611-34348A). The prospective cohort study was conducted from December 2016 to December 2017 in a commercial dairy herd with a total of 10, 000 lactating Jersey and crossbred cows, located on 3 different sites in Minnesota. Cows enrolled in the current study were a subset of a larger experiment to evaluate the association between HL and fertility of lactating dairy cows. A detailed description of the study design and animal management has been reported in Omontese et al. (2020).

Briefly, cows were housed in a cross-ventilated freestall barn with stalls bedded with recycled sand. Barn alleys had grooved concrete flooring and were scraped 3 times per day. Cows were fed a TMR (corn silage, alfalfa hay, and concentrates) formulated according to NRC
(2001) and had ad libitum access to water. Cows were milked 3 times daily at 0500, 1300, and $2100 \mathrm{~h}$ in a rotary milking parlor (GEA technologies, Bönen, Germany). The yearly rolling herd average for milk yield was approximately $7,711 \mathrm{~kg}$. A combination of estrus detection and timed AI using Cosynch 72 protocol was used for fertility management in the herd.

\section{Experimental Design}

Jersey cows $(\mathrm{n}=435)$ without any visible lesions on all 4 legs following hoof examination were enrolled at 20 \pm 3 DIM and evaluated for BCS according on a scale of 1 to 5 , with 0.25 increments of 0.25 units $(1=$ thin, 5 = fat), as described for dairy cows (Edmonson et al., 1989). At d 20, activity data loggers for automatic recording of daily activity were attached to the right hind leg of the cows. At $120 \pm 3$ DIM, cows were reexamined for HL and BCS, and the activity loggers were removed. For all hoof examinations, cows were restrained in a hydraulic stand-up chute (Appleton Single Leg Restraint, Appleton Steel Inc., Appleton, WI). A diagram of experimental procedures is shown in Figure 1. Hoof examinations on d 20 and 120 were completed by 2 veterinarians trained by the corresponding author. At d 20 hoof examination, excess fecal material on hooves was removed using a hoof knife, to facilitate visual inspection. Only cows without any visible HL at d 20 were enrolled. At the 120-d hoof examination, cows were assessed for HL, including sole hemorrhage (SH), sole ulcer, white line disease, digital dermatitis, and foot rot (Cramer et al., 2008; Omontese et al., 2020). At d 20 and d 120 hoof examinations, cows identified with HL received either a therapeutic hoof trim, application of hoof block, or topical antibiotics, depending on HL type and in accordance with standard farm procedures. All HL were recorded using an electronic hand-held device (Mesa, Juniper Systems, Logan, UT) that ran Pocket Trimmer (Valley Agricultural Software, Tulare, $\mathrm{CA}$ ), and data were synced with the farm computer, equipped with DairyComp 305 herd management software (Valley Agricultural Software).

\section{Behavioral Data Collection}

Data on lying behavior (daily lying duration, number of lying bouts, lying bout duration) and number of steps from d 20 to d 120 were recorded continuously using electronic data loggers (AfiTag II, AfiMilk, Afikim, Israel) validated for recording activity of lactating dairy cows (Henriksen and Munksgaard, 2019). AfiTag II sensors were attached to the cow's right hind leg with a plastic strap for the duration of the study. The AfiTag II device records information via a posture sen- 


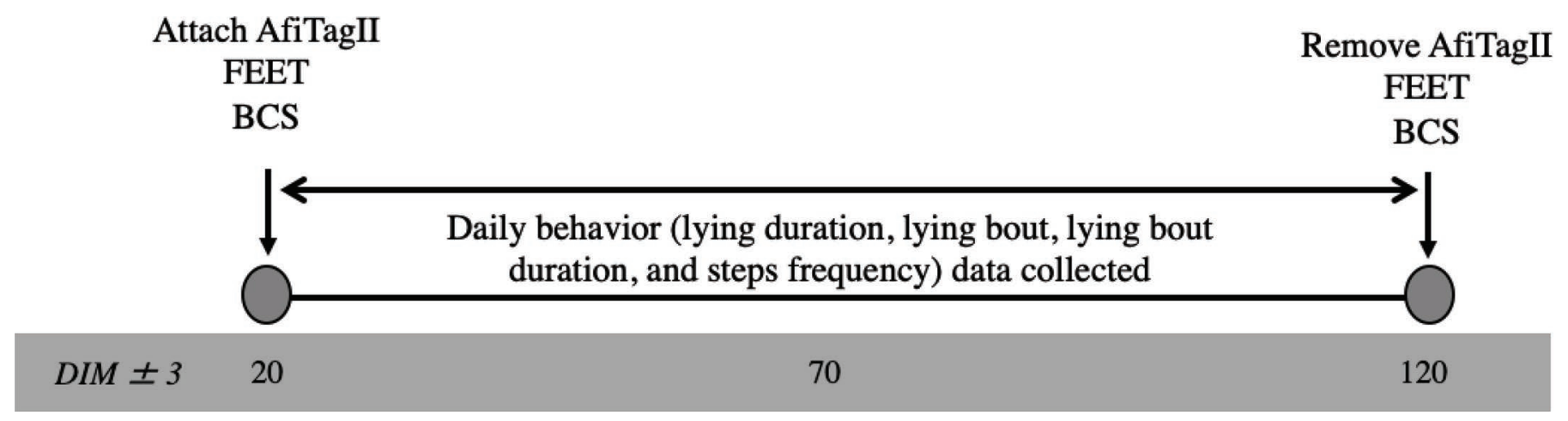

Figure 1. Timeline of experimental procedures. FEET = evaluation of foot for hoof lesion status at d 20 and d 120; only cows without hoof lesions upon examination at d 20 were enrolled. BCS = evaluation of body condition score.

sor technique, including 3-dimensional accelerations. During each milking event, the accumulated activity data transmitted by the accelerometers were received by a wireless antenna linked to the AfiFarm management software (AfiMilk). Recorded data were analyzed by the AfiFarm software to calculate daily lying duration, number of lying bouts, lying bout duration, and number of steps. On completion of the study, behavior data were exported from the AfiFarm software into an Excel 2013 spreadsheet (Microsoft Corp., Redmond, WA).

\section{Statistical Analyses}

Due to data backup failures, behavior data from only 344 cows out of the 435 enrolled in the study were available for analysis. Initially, analyses were performed using only cows $(\mathrm{n}=126)$ with complete daily (d 20 to d 120) observations. Model estimates were then compared with data from all cows, including those with fewer than $100 \mathrm{~d}$ of daily observations. Because model estimates did not differ, all behavior data were used, resulting in a total of $24,813 \mathrm{~d}$ of behavior data from 344 cows during a single lactation. Behavior data on the first day of enrollment and last day of the study were considered outliers because of time spent separated from the herd due to study protocols, and were not used for model fitting. Behavior data from cows that were culled $(\mathrm{n}=6)$ or removed from the herd $(\mathrm{n}=$ 85 ) before HL status could be determined at d 120 were excluded from final analyses.

Descriptive statistics and graphical data analysis were completed using Stata 14.1 (StataCorp, College Station, TX). Separate models were built for each daily behavior of interest (daily lying duration, number of lying bouts, lying bout duration, or number of steps). All models included the fixed effects of lesion status at d 120, DIM, interaction between lesion status at d 120 and DIM, parity (primiparous, second lactation, multiparous), change in BCS (maintained, gained, lost), and season of calving: winter (December to February), spring (March to May), or summer (June to August). Extreme values were carefully examined, and analyses were performed with and without their presence. Because including extreme behavior values did not affect estimates, all data were included in the analyses. Data were analyzed using restricted maximum likelihood linear mixed models with an autoregressive covariance structure. The outcome of interest was each measure of daily lying behavior (lying duration, number of lying bouts, lying bout duration) and daily number of steps.

To evaluate the association between behavior and $\mathrm{HL}$, cows were categorized into healthy (no HL at d 120 ) or lesion (with any HL at d 120). Analysis showed that lying duration was different between cows that later developed $\mathrm{SH}$ versus cows that were healthy at d 120; thus a separate model was built to evaluate the association between lying duration and the number of feet affected with SH. Therefore, cows were recategorized as healthy (no lesion at d 120), SH in 1 foot at d $120, \mathrm{SH}$ in 2 feet at d 120, or SH in 3 or 4 feet at d 120.

\section{RESULTS}

\section{Descriptive Statistics}

Behavior data from a total of 344 cows, primiparous $(\mathrm{n}=183)$, second lactation $(\mathrm{n}=68)$, and multiparous $(\mathrm{n}=93)$, were available for statistical analyses (Table 1). Incidence of HL and HL category at d 120 are shown in Table 1. Fifty-eight percent of cows (201 out of 344 ) had a HL at d 120. Of the total number of HL diagnosed at d 120, 88\% (177 of 201) were SH. Considering that the majority of HL at d 120 were $\mathrm{SH}$, cows were regrouped according to the number of feet with SH. Fewer cows had SH in 3 or 4 feet (6.9\%) 
Table 1. Incidence of hoof lesions at d 120 during the prospective cohort study of the association between behavior and hoof lesions in lactating Jersey cows $(\mathrm{n}=344)$ according to parity, season of calving, and change in BCS

\begin{tabular}{|c|c|c|}
\hline Item & No. & $\%$ \\
\hline \multicolumn{3}{|c|}{ Lesion status at d 120} \\
\hline Healthy & 143 & 41.6 \\
\hline Lesion & 201 & 58.4 \\
\hline \multicolumn{3}{|c|}{ Lesion category at d 120} \\
\hline Healthy & 143 & 41.6 \\
\hline Hemorrhage & 177 & 51.5 \\
\hline Noninfectious $^{1}$ & 15 & 4.4 \\
\hline Infectious $^{2}$ & 8 & 2.3 \\
\hline \multicolumn{3}{|c|}{ Hemorrhage status at d 120} \\
\hline Healthy & 143 & 41.6 \\
\hline 1 foot & 89 & 25.9 \\
\hline 2 feet & 79 & 22.9 \\
\hline 3 and 4 feet & 24 & 6.9 \\
\hline \multicolumn{3}{|l|}{ Parity } \\
\hline 1 & 183 & 53.2 \\
\hline 2 & 68 & 19.8 \\
\hline $3+$ & 93 & 26.7 \\
\hline \multicolumn{3}{|l|}{ Season of calving } \\
\hline Spring & 126 & 36.6 \\
\hline Summer & 148 & 43.0 \\
\hline Winter & 70 & 20.3 \\
\hline \multicolumn{3}{|l|}{ BCS change } \\
\hline Maintained & 300 & 87.2 \\
\hline Increased & 21 & 6.1 \\
\hline Decreased & 22 & 6.4 \\
\hline
\end{tabular}

${ }^{1}$ Noninfectious lesions were sole ulcer and white line disease at d 120 . Seven cows with noninfectious lesion also had a sole hemorrhage on a different foot.

${ }^{2}$ Infectious lesion was digital dermatitis at d 120 . Five cows with infectious lesion also had a sole hemorrhage on a different foot. compared with cows that had $\mathrm{SH}$ in 1 foot $(25.9 \%)$ or 2 feet $(22.9 \%$; Table 1$)$.

\section{Daily Lying Behavior (Lying Duration, Number of Bouts, Lying Bout Duration)}

Table 2 shows the final model regression estimates for total daily lying duration (hours per day). Model adjusted lying duration for cows in this study was 10.1 h/d (95\% CI: 9.8 to 10.3). Compared with healthy lactating Jersey cows, cows that developed HL had a $0.5 \mathrm{~h} / \mathrm{d}(95 \% \mathrm{CI}: 0.4$ to $0.8 ; P<0.001)$ shorter lying duration. Jersey cows that developed SH in 1 foot or 2 feet had a $0.7 \mathrm{~h} / \mathrm{d}(95 \%$ CI: 0.4 to 1.0$)$ and $0.5 \mathrm{~h} / \mathrm{d}$ (95\% CI: 0.1 to $0.8 ; P<0.001)$ decreased lying duration, respectively, compared with healthy $(11.03 \mathrm{~h} / \mathrm{d}$; 95\% CI: 10.68 to 11.38; $P<0.001$ ) Jersey cows (Table $3)$. Irrespective of lesion status at d 120, overall lying duration of lactating cows increased gradually from $\mathrm{d}$ 20 to d 120 (Figure 2).

Model adjusted number of lying bouts was 12.4 (95\% CI: 12.0 to 12.9 ) bouts per day. We found no evidence for a difference in the number of lying bouts in Jersey cows that developed HL $(0.4 ; 95 \%$ CI; -0.8 to $1.6 ; P$ $=0.49)$ compared with cows that remained healthy (Table 4). However, number of lying bouts decreased gradually both for Jersey cows that remained healthy and for those that developed HL by d 120 (Figure 3).

Table 2. Final mixed model $^{1}$ for daily lying duration (hours per day) of lactating Jersey cows $(\mathrm{n}=344)$ according to hoof lesion status at d 120

\begin{tabular}{|c|c|c|c|}
\hline Predictor & Estimate & $95 \% \mathrm{CI}$ & $P$-value \\
\hline Intercept & 10.06 & 9.83 to 10.29 & $<0.001$ \\
\hline \multicolumn{4}{|l|}{ Status at d 120} \\
\hline Healthy $^{2}$ & Ref. $^{3}$ & & \\
\hline Lesion & -0.53 & -0.78 to -0.28 & $<0.001$ \\
\hline DIM & 0.006 & 0.005 to 0.007 & $<0.001$ \\
\hline \multicolumn{4}{|c|}{ Status at d $120 \times$ DIM } \\
\hline Healthy $\times$ DIM & Ref. & & \\
\hline Lesion $\times$ DIM & 0.003 & 0.002 to 0.005 & $<0.001$ \\
\hline \multicolumn{4}{|l|}{ Lactation } \\
\hline 1 & Ref. & & \\
\hline 2 & 0.85 & 0.54 to 1.17 & $<0.001$ \\
\hline $3+$ & 1.33 & 1.03 to 1.63 & $<0.001$ \\
\hline \multicolumn{4}{|l|}{ BCS change } \\
\hline Maintained & Ref. & & \\
\hline Increased & 0.20 & -0.25 to 0.65 & 0.38 \\
\hline Decreased & -0.40 & -0.84 to 0.03 & 0.07 \\
\hline \multicolumn{4}{|l|}{ Season } \\
\hline Spring & Ref. & & \\
\hline Summer & 0.009 & -0.26 to 0.24 & 0.94 \\
\hline Winter & -0.98 & -1.36 to -0.60 & $<0.001$ \\
\hline
\end{tabular}

${ }^{1}$ Total log-likelihood from model $=-43,026.69$; null model $=-43,509.97$.

${ }^{2}$ Healthy $=$ cows without any hoof lesion from d 20 to $\mathrm{d} 120(\mathrm{n}=143)$; lesion $=$ cows with no lesion at $\mathrm{d} 20$ that developed lesion by d $120(\mathrm{n}=201)$.

${ }^{3}$ Referent 
Model adjusted lying bout duration was $46.7 \mathrm{~min}$ (95\% CI: 43.42 to 49.96 ). Lying bout duration decreased 3.1 min per bout $(95 \%$ CI: -6.6 to $0.5 ; P=0.09$; Table $5)$ between cows diagnosed with lesion and cows that remained healthy at d 120 . However, regardless of lesion status at d 120, lying bout duration increased in cows from d 20 to d 120 (Figure 4).

\section{Number of Steps}

Model adjusted steps were 4,476.5 (95\% CI: 4,336.9 to $4,615.9)$ per day. We found no evidence for a difference in the daily number of steps among cows that remained healthy at d 120 compared with cows that developed HL (62.1 steps/d; 95\% CI: -89.6 to $213.9 ; P$ $=0.42$; Table 6 ). In the current study, number of steps decreased from d 20 to d 120 regardless of lesion status at d 120 (Figure 5).

\section{DISCUSSION}

To the best of our knowledge, this is the first longitudinal study to evaluate the association between lying behavior and HL development in Jersey cows. Of the HL observed in the current study, SH had the greatest incidence. It is possible that more severe infectious or noninfectious HL could have led to different behavioral outcomes; hence, interpretation of the results of this study should consider differences in herd characteristics and management systems. Our study demonstrated that in early lactation (d 20), lying duration of apparently healthy cows was already decreased in cows that went on to develop HL, compared with herd mates that remained healthy at mid-lactation (d 120). The shorter lying duration at d 20 of apparently healthy cows that went on to develop HL suggests that HL pathogenesis likely started before enrollment of cows in the study. The decreased lying duration in the current study corroborates the findings of Chapinal et al. (2009), who reported that cows who developed either sole ulcers or SH had decreased lying time compared with healthy cows during the transition period. Owing to the current study design, in which cows were assessed for HL initially at d 20 and later at d $120(\sim 100-d$ interval $)$, it was difficult to characterize the exact period when HL became visible in individual Jersey cows. Nonetheless, the reduced lying duration before enrollment among cows that developed HL in our study indicates that behavioral changes precede the appearance of HL. Furthermore, the interval from enrollment to HL diagnosis in this study was about 14 wk after calving and corresponds to the 8- to 14-wk period of hoof growth from

Table 3. Final mixed model ${ }^{1}$ for daily lying duration (hours per day) of lactating Jersey cows $(\mathrm{n}=336$ ) according to number of feet with sole hemorrhage at $d 120$

\begin{tabular}{|c|c|c|c|}
\hline Predictor & Estimate & $95 \% \mathrm{CI}$ & $P$-value \\
\hline Intercept & 11.03 & 10.68 to 11.38 & $<0.001$ \\
\hline \multicolumn{4}{|l|}{ Status at d 120} \\
\hline Healthy $^{2}$ & Ref. $^{3}$ & & \\
\hline Hemorrhage 1 foot & -0.65 & -0.95 to -0.35 & $<0.001$ \\
\hline Hemorrhage 2 feet & -0.45 & -0.76 to -0.13 & 0.005 \\
\hline Hemorrhage 3 and 4 feet & -0.36 & -0.85 to 0.13 & 0.15 \\
\hline DIM & 0.006 & 0.005 to 0.007 & $<0.001$ \\
\hline \multicolumn{4}{|l|}{ Status at d $120 \times \mathrm{DIM}$} \\
\hline Healthy $\times$ DIM & Ref. & & \\
\hline Hemorrhage 1 foot $\times$ DIM & 0.002 & 0.0002 to 0.004 & 0.035 \\
\hline Hemorrhage 2 feet $\times$ DIM & 0.005 & 0.002 to 0.007 & $<0.001$ \\
\hline Hemorrhage 3 and 4 feet $\times$ DIM & 0.001 & -0.003 to 0.005 & 0.554 \\
\hline \multicolumn{4}{|l|}{ Lactation } \\
\hline 1 & Ref. & & \\
\hline 2 & -0.95 & -1.26 to -0.63 & $<0.001$ \\
\hline $3+$ & 0.29 & -0.03 to 0.62 & 0.071 \\
\hline \multicolumn{4}{|l|}{ BCS change } \\
\hline Maintained & Ref. & & \\
\hline Increased & 0.28 & -0.17 to 0.72 & 0.23 \\
\hline Decreased & -0.42 & -0.84 to 0.01 & 0.06 \\
\hline \multicolumn{4}{|l|}{ Season } \\
\hline Spring & Ref. & & \\
\hline Summer & -0.044 & -0.29 to 0.19 & 0.72 \\
\hline Winter & -0.98 & -1.36 to -0.62 & $<0.001$ \\
\hline
\end{tabular}

${ }^{1}$ Total log-likelihood from model $=-41,786.19 ;$ null model $=-42,244.48$.

${ }^{2}$ Healthy $=$ cows without any hoof lesion from d 20 to d $120(\mathrm{n}=143)$. Hemorrhage on 1 foot at d 120: $\mathrm{n}=$ 89. Hemorrhage on 2 feet at d 120: $\mathrm{n}=79$. Hemorrhage on 3 or 4 feet at $\mathrm{d} 120: \mathrm{n}=24$.

${ }^{3}$ Referent 


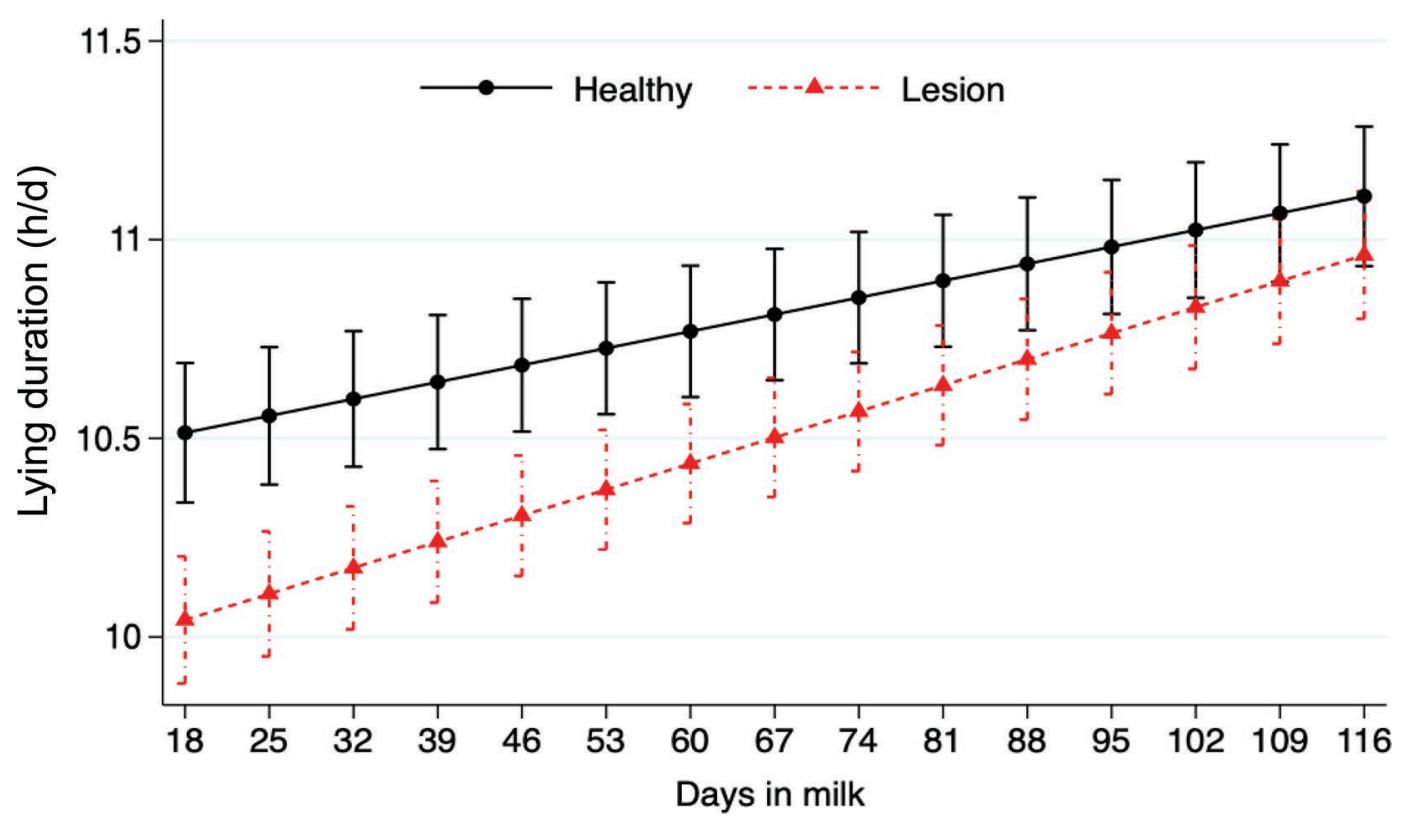

Figure 2. Predicted daily lying duration and 95\% CI of lactating Jersey cows that were designated healthy [no hoof lesion (HL) at d 20 and $\mathrm{d} 120 ; \mathrm{n}=143$ ] or diagnosed with lesion (no HL at $\mathrm{d} 20$ but HL at $\mathrm{d} 120 ; \mathrm{n}=201$ ). Lying duration estimate for the interaction between HL status at d 120 and DIM in lactating Jersey cows with HL at d 120 was $0.003 \mathrm{~h} / \mathrm{d}(95 \%$ CI: 0.002 to $0.005 ; P<0.001)$.

the sole to the corium reported for lactating Holstein cows (Leach et al., 1997; van Amstel et al., 2016).

Recent work by Newsome et al. (2016) suggests that inflammatory changes during the transition period play a crucial role in hoof horn lesion development by caus- ing exostosis on the third phalanx. Their hypothesis is supported by studies that have identified the peripartum phase as an important risk period associated with biomechanical and histopathological changes to the hoof (Tarlton et al., 2002; Bergsten et al., 2015;

Table 4. Final mixed model ${ }^{1}$ for daily number of lying bouts of lactating Jersey cows $(\mathrm{n}=344)$ according to hoof lesion status at d 120

\begin{tabular}{|c|c|c|c|}
\hline Predictor & Estimate & $95 \% \mathrm{CI}$ & $P$-value \\
\hline Intercept & 12.40 & 12.03 to 12.78 & $<0.001$ \\
\hline \multicolumn{4}{|l|}{ Status at $\mathrm{d} 120$} \\
\hline Healthy $^{2}$ & Ref. $^{3}$ & & \\
\hline Lesion & 0.41 & -0.76 to 1.59 & 0.49 \\
\hline DIM & -0.03 & -0.02 to -0.03 & $<0.001$ \\
\hline \multicolumn{4}{|c|}{ Status at d $120 \times$ DIM } \\
\hline Healthy $\times$ DIM & Ref. & & \\
\hline Lesion $\times$ DIM & -0.0002 & 0.002 to -0.003 & 0.84 \\
\hline \multicolumn{4}{|l|}{ Parity } \\
\hline 1 & Ref. & & \\
\hline 2 & -1.99 & -2.50 to -1.47 & $<0.001$ \\
\hline $3+$ & -1.95 & -2.44 to -1.46 & 0.95 \\
\hline \multicolumn{4}{|l|}{ BCS change } \\
\hline Maintained & Ref. & & \\
\hline Increased & 0.12 & -0.61 to 0.86 & 0.75 \\
\hline Decreased & -0.15 & -0.87 to 0.57 & 0.68 \\
\hline \multicolumn{4}{|l|}{ Season } \\
\hline Spring & Ref. & & \\
\hline Summer & -0.35 & -0.75 to 0.06 & 0.095 \\
\hline Winter & -2.32 & -2.94 to -1.70 & $<0.001$ \\
\hline
\end{tabular}

${ }^{1}$ Total log-likelihood from model $=-52,972.62$; null model $=-53,907.36$.

${ }^{2}$ Healthy $=$ cows without any hoof lesion from d 20 to $\mathrm{d} 120(\mathrm{n}=143)$; lesion $=$ cows with no lesion at d 20 that developed lesion by d $120(\mathrm{n}=201)$.

${ }^{3}$ Referent. 
Table 5. Final mixed model ${ }^{1}$ for daily lying bout duration (minutes per bout) of lactating Jersey cows $(\mathrm{n}=$ 344 ) according to hoof lesion status at d 120

\begin{tabular}{|c|c|c|c|}
\hline Predictor & Estimate & $95 \% \mathrm{CI}$ & $P$-value \\
\hline Intercept & 46.7 & 43.4 to 49.9 & $<0.001$ \\
\hline \multicolumn{4}{|l|}{ Status at d 120} \\
\hline Healthy $^{2}$ & Ref. $^{3}$ & & \\
\hline Lesion & -3.04 & -6.6 to 0.49 & 0.09 \\
\hline DIM & 0.26 & 0.24 to 0.28 & $<0.001$ \\
\hline \multicolumn{4}{|c|}{ Status at d $120 \times$ DIM } \\
\hline Healthy $\times$ DIM & Ref. & & \\
\hline Lesion $\times$ DIM & 0.02 & -0.005 to 0.04 & 0.12 \\
\hline \multicolumn{4}{|l|}{ Parity } \\
\hline 1 & Ref. & & \\
\hline 2 & 23.93 & 19.4 to 28.4 & $<0.001$ \\
\hline $3+$ & 26.3 & 22.1 to 30.6 & $<0.001$ \\
\hline \multicolumn{4}{|l|}{ BCS change } \\
\hline Maintained & Ref. & & \\
\hline Increased & 0.32 & -6.19 to 6.64 & 0.95 \\
\hline Decreased & -2.88 & -9.12 to 3.36 & 0.37 \\
\hline \multicolumn{4}{|l|}{ Season } \\
\hline Spring & Ref. & & \\
\hline Summer & 3.16 & -0.38 to 6.69 & 0.08 \\
\hline Winter & 16.01 & 10.63 to 21.04 & $<0.001$ \\
\hline
\end{tabular}

${ }^{1}$ Total log-likelihood from model $=-106,275.44$; null model $=-106,728.41$.

${ }^{2}$ Healthy $=$ cows without any hoof lesion from d 20 to d 120 ( $\left.\mathrm{n}=143\right)$; lesion $=$ cows with no lesion at d 20 that developed lesion by d $120(\mathrm{n}=201)$.

${ }^{3}$ Referent.

Lim et al., 2015). It is unclear what specific role inflammation played in our study, because it is possible that inflammatory changes were a response to or the cause of the changes in lying duration during the early postpartum period. Similarly, changes in lying behavior of cows during the early postpartum period have been associated with development of hoof horn disruption lesions in mid-lactation (Dippel et al., 2011; Sepúlveda-

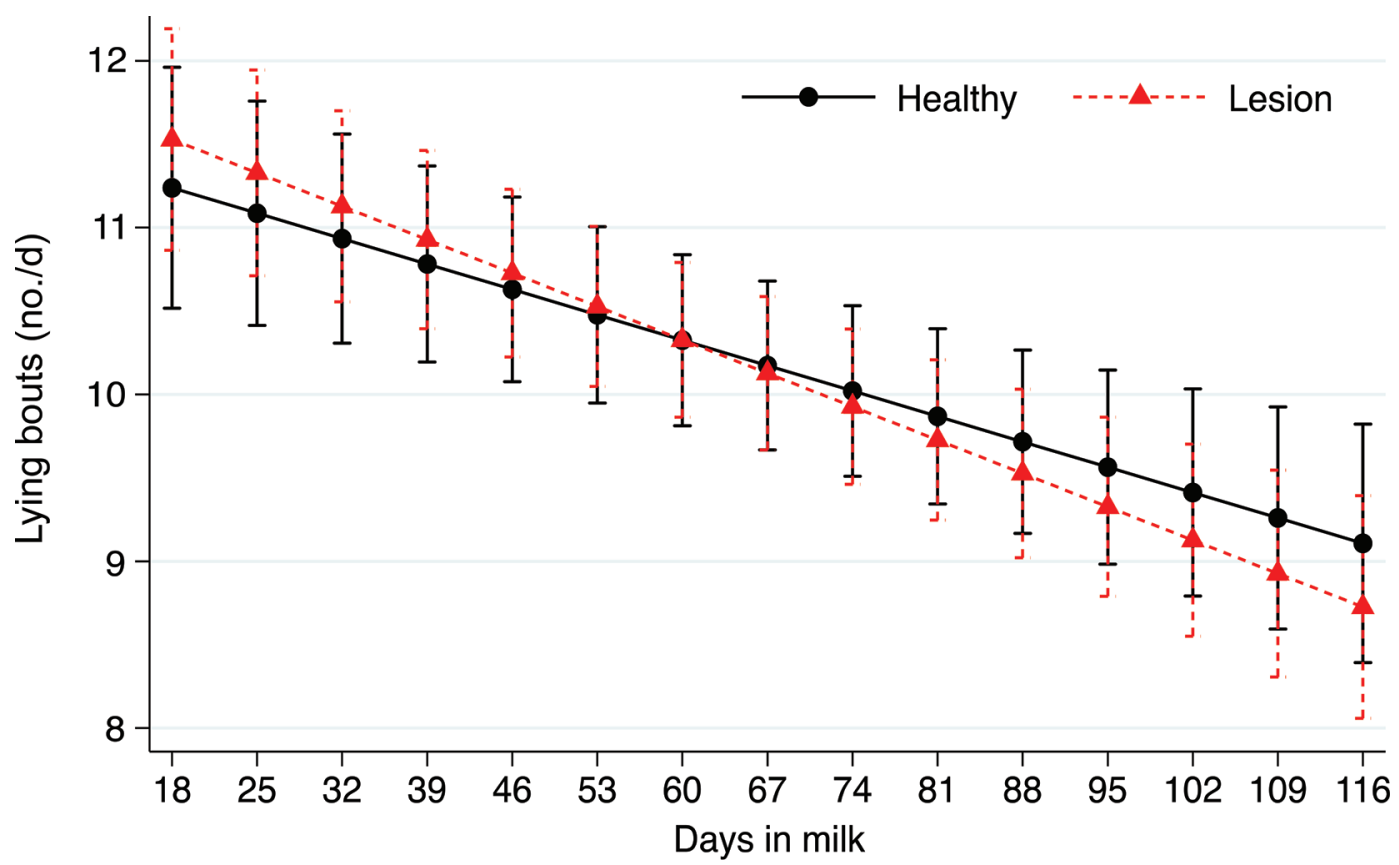

Figure 3. Predicted daily number of lying bouts and 95\% CI of lactating Jersey cows that were designated healthy [no hoof lesion (HL) at d 20 and $\mathrm{d} 120 ; \mathrm{n}=143$ ] or diagnosed with lesion (no HL at d 20 but HL at d 120; $\mathrm{n}=201$ ). Number of lying bouts estimate for the interaction between HL status at d 120 and DIM in lactating Jersey cows with HL at d 120 was -0.0002 bouts per day $(95 \%$ CI: -0.0003 to $0.002 ; P=0.84$ ). 
Table 6. Final mixed model ${ }^{1}$ for daily number of steps (number per day) of lactating Jersey cows $(\mathrm{n}=344)$ according to hoof lesion status at d 120

\begin{tabular}{lccc}
\hline Predictor & Estimate & $95 \%$ CI & $P$-value \\
\hline Intercept & $4,476.5$ & $4,336.9$ to $4,615.9$ & $<0.001$ \\
Status at d 120 & Ref. $^{3}$ & & \\
Healthy & 62.14 & -89.62 to 213.91 & 0.42 \\
Lesion & -2.18 & -2.94 to -1.41 & $<0.001$ \\
DIM & & & \\
Status at d 120 $\times$ DIM & Ref. & -0.97 to 1.13 & 0.88 \\
Healthy $\times$ DIM & 0.08 & & \\
Lesion $\times$ DIM & & & $<0.001$ \\
Parity & Ref. & -719.8 to -341.9 & \\
1 & -530.87 & & 0.001 \\
2 & -825.71 & -167.6 to 372.6 & 0.45 \\
$3+$ & & -194.2 to 332.2 & \\
BCS change & Ref. & & 0.25 \\
Maintained & 102.51 & -61.5 to 235.8 & 0.13 \\
Increased & 68.9 & -403.3 to 51.1 & \\
Decreased & & & \\
Season & Ref. & 87.14 & \\
Spring & -176.1 & & \\
Summer & Winter & & \\
\hline
\end{tabular}

${ }^{1}$ Total log-likelihood from model $=-201,786.43$; null model $=-202,354.51$.

${ }^{2}$ Healthy $=$ cows without any hoof lesion from d 20 to d $120(\mathrm{n}=143)$; lesion $=$ cows with no lesion at d 20 that developed lesion by d $120(\mathrm{n}=201)$.

${ }^{3}$ Referent.

Varas et al., 2018). Furthermore, hormonal changes at the time of parturition appear to be associated with noninflammatory changes in the connective tissues of the hoof, which consequently impair the resilience of the hoof to external stresses (Knott et al., 2007) and would allow increased forces on the corium that could result in inflammation. To elucidate the temporal relationship between lying duration and inflammation, it

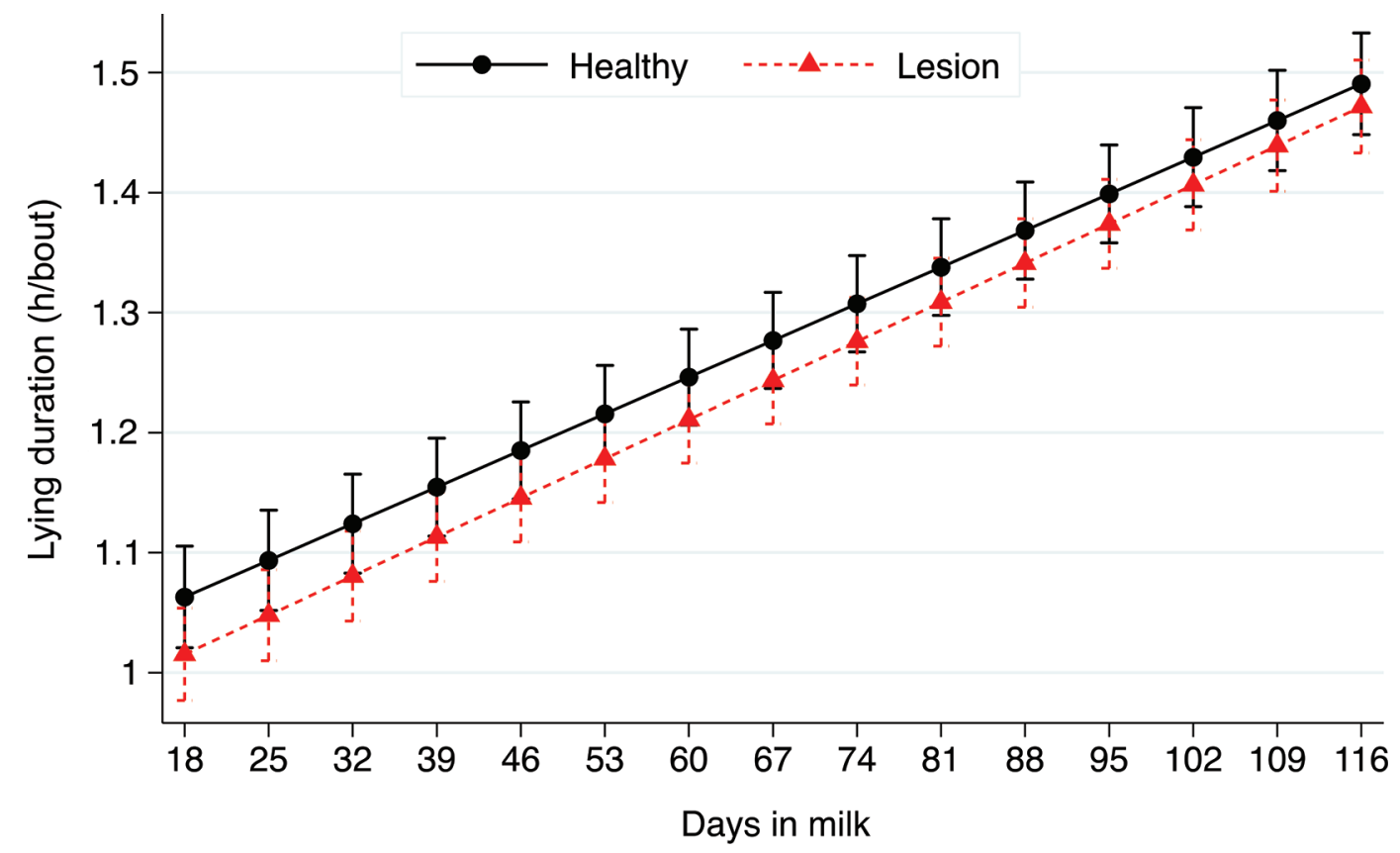

Figure 4. Predicted daily lying bout duration (hours per day) and 95\% CI of lactating Jersey cows that were designated healthy [no hoof lesion (HL) at d 20 and d 120; $\mathrm{n}=143$ ] or diagnosed with lesion (no HL at d 20 but HL at d 120; $\mathrm{n}=201$ ). Lying bout duration estimate for the interaction between HL status at d 120 and DIM in lactating Jersey cows with HL at d 120 was $0.02 \mathrm{~h}(95 \%$ CI: -0.005 to $0.04 ; P=0.84$ ). 


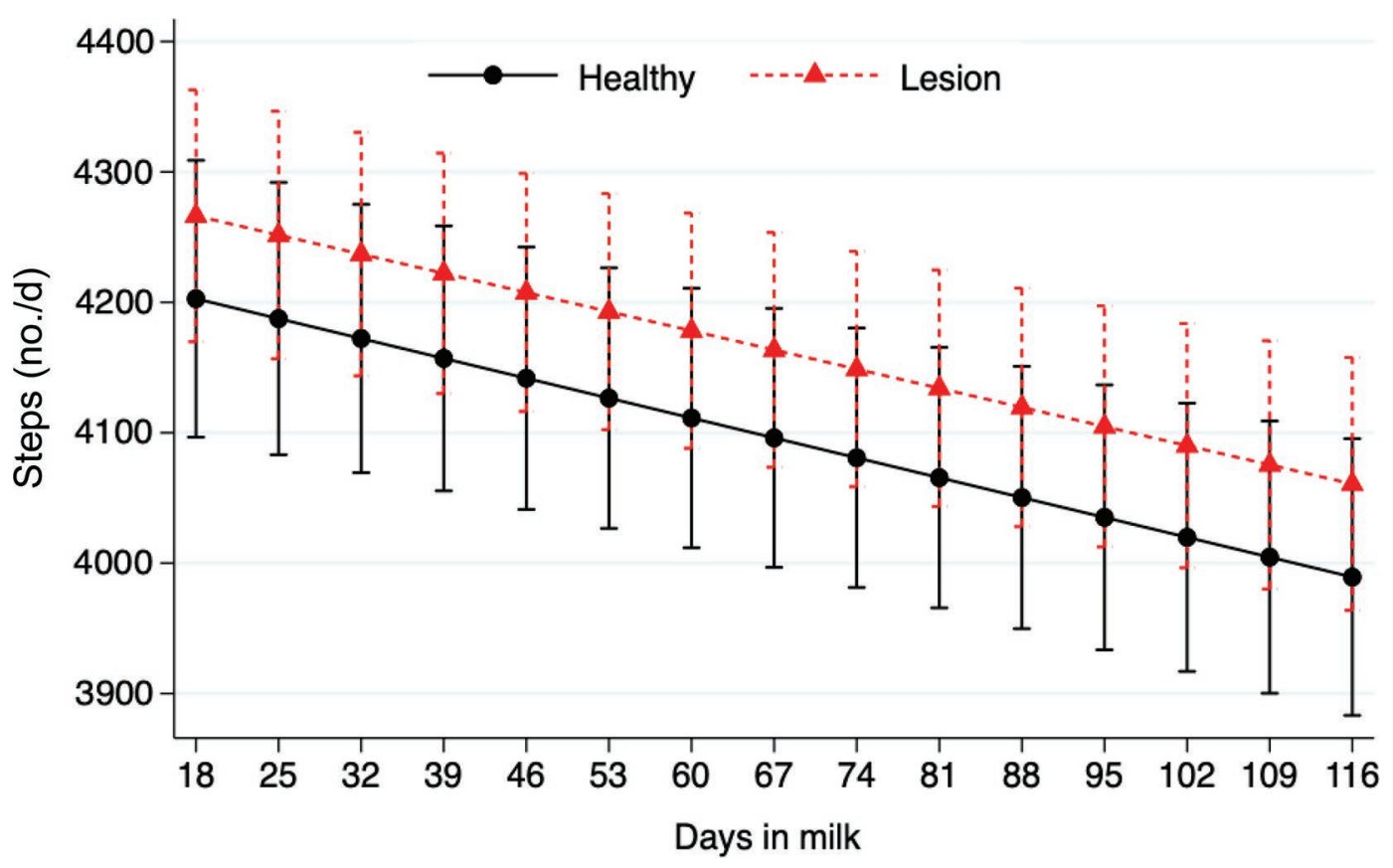

Figure 5. Predicted daily number of steps and 95\% CI of lactating Jersey cows that were designated healthy [no hoof lesion (HL) at d 20 and $\mathrm{d} 120 ; \mathrm{n}=143$ ] or diagnosed with lesion (no HL at $\mathrm{d} 20$ but HL at d 120; $\mathrm{n}=201$ ). Steps per day estimate for the interaction between HL status at d 120 and DIM in lactating Jersey cows with HL at d 120 was 0.08 steps per day (95\% CI: -0.97 to $1.13 ; P=0.88$ ).

is clear that future longitudinal studies should observe cows during the dry period to measure inflammation mediators.

Chapinal et al. (2009) reported that cows that developed ulcers had a faster decline in lying duration before calving and had a faster increase after calving. In a separate study, Proudfoot et al. (2010) reported that Holstein cows diagnosed with lesions in mid-lactation spent more time standing and consumed feed at a faster rate than cows without lesions shortly before and after calving. Considering the aforementioned findings and the observations in our current study, it is plausible that HL development is preceded by reduced lying time and increased standing duration, both of which are related to feeding behavior and cow comfort in the peripartum period (Huzzey et al., 2005). Lying duration is an important behavior in lactating dairy cows, and decreased daily lying duration can be indicative of compromised cow welfare and comfort (Munksgaard et al., 2005). Reduced lying duration has also been associated with elevated cortisol concentrations in cows with restricted ability to lie down (Munksgaard and Simonsen, 1996; Cooper et al., 2008), stress (EFSA, 2009), and decreased milk production (Munksgaard et al., 2005).

The relationship between HL and standing behavior may be linked to the increased propensity to feed at a faster rate and for a much longer duration to satisfy the nutritional requirements needed for high milk yield (Fregonesi and Leaver, 2002). This is supported by the finding that feeding and rumination duration is negatively correlated with lying duration (Schirmann et al., 2012; Grimm et al., 2019). Also, higher milk production and increased feeding rate have been attributed to greater nutritional demands, especially as lactation progresses from early to mid-lactation (Vasseur et al., 2012; Løvendahl and Munksgaard, 2016; Maselyne et al., 2017). On the other hand, lying time is a higherpriority behavior than feeding or social contact (Jensen et al., 2005; Munksgaard et al., 2005). As reviewed by Cook (2020), individual variations may occur between cows as far as their optimum lying time, below which the HL development pathway is initiated.

We did not observe evidence of a difference in the number of steps of Jersey cows that remained healthy compared with cows that developed HL in our study. Only a few studies have reported that number of steps may be a good predictor of lameness in lactating cows (Chapinal and Tucker, 2012; de Mol et al., 2013; Thorup et al., 2015). Considering that we found no evidence for differences in the number of steps, even though lying duration in the early postpartum period was reduced in cows that developed HL compared with cows that remained healthy, it is possible that cows that developed HL might have stood for longer periods to feed, in response to the demands of higher milk production, 
compared with cows that remained healthy. Previous studies have shown associations between higher milk yield and feeding time (Fregonesi and Leaver, 2002) and lameness (Green et al., 2002) in lactating Holstein cows. Future studies can take advantage of precision technology that can characterize standing duration, feeding duration, and lying duration of lactating dairy cows to further elucidate the relationships between these behaviors and HL development.

Decreases in daily lying duration can occur through fewer number of lying bouts, shorter lying bout duration, or both. Similar to our findings, Chapinal et al. (2009) reported no evidence of differences in number of lying bouts or lying bout duration in cows that went on to develop sole ulcers. Proudfoot et al. (2010) did report differences in both the number of standing events and duration of each standing event only in the $24 \mathrm{~h}$ after calving. However, our study did not record lying behavior around the calving period. To accurately determine whether cows that develop HL have fewer lying bouts or shorter lying bout duration would require a prospective study with a larger sample size than that of our study or the other 2 studies mentioned. Changes in the number of lying bouts and lying bout duration have been reported in cows with HL (Chapinal et al., 2009; Thomsen et al., 2012) and likely reflect unwillingness of cows with HL to stand once they lie down.

Limitations of the current study included the problem related to data backup failures and a proportion of cows excluded from final analysis because they were moved to another location before lesion status at d 120 could be determined. Furthermore, SH scoring in the current study is limited in that it did not differentiate between diffused or circumscribed hemorrhage, as reported by Proudfoot et al. (2010) in Holstein cows. It should be noted that the majority of the HL in our study were $\mathrm{SH}$, and the diagnosis of $\mathrm{SH}$ has been shown to vary between hoof trimmers (Cramer et al., 2008; Holzhauer et al., 2006). Our study minimized variation in HL diagnosis by using 2 veterinarians trained by the corresponding author. Because at d 20 no horn was removed and no way currently exists to determine the presence of hemorrhage in deeper layers of the horn without hoof trimming, it is likely that we underdiagnosed the presence of hemorrhage at $\mathrm{d} 20$ and, in turn, overestimated the development of new $\mathrm{SH}$.

This study underscores the importance of earlylactation lying behavior in HL development, as well as the potential impact of lying behavior measurements in estimating cow comfort, including bedding depth and cleanliness (Wang et al., 2016; Cook, 2019). Taken in conjunction with other recent studies, our findings suggest that a combination of behavioral and metabolic changes pre- and postpartum might be required for de- velopment of HL. Also, lameness detection algorithms should consider including lying duration, in addition to standing and feeding behavior in early lactation, to serve as potential early indicators of HL development in mid-lactation. Finally, results from this study indicate the importance of lying duration as a parameter to be considered in the quest to develop automated methods of HL and lameness detection in dairy herds.

\section{CONCLUSIONS}

Our study found that lying duration was lower and remained so in Jersey cows that develop HL compared with cows that remained healthy from early to mid-lactation. This association was driven by the large number of cows that developed SH. We found no evidence for other clinically relevant differences in lying bout duration, lying bout number, and number of steps among Jersey cows that developed HL compared with cows that remained healthy. The difference in lying duration results from this study suggests that the pathogenesis of HL might have started before 20 DIM. Further research is needed to determine what causes the change in lying behavior in cows during the transition period that later develop HL.

\section{ACKNOWLEDGMENTS}

The authors thank the owners and staff of Davis Family Dairies (Nicollet, MN, and Le Sueur, MN) for the use of their cows and facilities and for their assistance during experimental procedures. We thank Aaron Rendahl (University of Minnesota, Saint Paul, MN) for his help with the statistical analyses. Financial support for this project was provided by a grant from Rapid Agricultural Response Minnesota Fund and the University of Minnesota (St. Paul). The assistance of graduate and summer students of the University of Minnesota (Saint Paul) during farm visits is appreciated. The authors have no conflicts of interest to declare.

\section{REFERENCES}

Alsaaod, M., M. Fadul, and A. Steiner. 2019. Automatic lameness detection in cattle. Vet. J. 246:35-44. https://doi.org/10.1016/j .tvj1.2019.01.005.

Bergsten, C., E. Telezhenko, and M. Ventorp. 2015. Influence of soft or hard floors before and after first calving on dairy heifer locomotion, claw and leg health. Animals (Basel) 5:662-686. https://doi .org/10.3390/ani5030378.

Chapinal, N., A. M. de Passillé, D. M. Weary, M. A. G. von Keyserlingk, and J. Rushen. 2009. Using gait score, walking speed, and lying behavior to detect hoof lesions in dairy cows. J. Dairy Sci. 92:4365-4374. https://doi.org/10.3168/jds.2009-2115.

Chapinal, N., and C. B. Tucker. 2012. Validation of an automated method to count steps while cows stand on a weighing platform 
and its application as a measure to detect lameness. J. Dairy Sci. 95:6523-6528. https://doi.org/10.3168/jds.2012-5742.

Charlton, G. L., V. Bouffard, J. Gibbons, E. Vasseur, D. B. Haley, D. Pellerin, J. Rushen, and A. M. de Passillé. 2016. Can automated measures of lying time help assess lameness and leg lesions on tiestall dairy farms? Appl. Anim. Behav. Sci. 175:14-22. https://doi .org/10.1016/j.applanim.2015.02.011.

Cook, N. B. 2019. Optimizing resting behavior in lactating dairy cows through freestall design. Vet. Clin. North Am. Food Anim. Pract. 35:93-109. https://doi.org/10.1016/j.cvfa.2018.10.005.

Cook, N. B. 2020. Symposium review: The impact of management and facilities on cow culling rates. J. Dairy Sci. 103:3846-3855. https:/ /doi.org/10.3168/jds.2019-17140.

Cooper, M. D., D. R. Arney, and C. J. C. Phillips. 2008. The effect of temporary deprivation of lying and feeding on the behaviour and production of lactating dairy cows. Animal 2:275-283. https://doi .org/10.1017/S1751731107001164

Cramer, G., K. D. Lissemore, C. L. Guard, K. E. Leslie, and D. F. Kelton. 2008. Herd- and cow-level prevalence of foot lesions in Ontario dairy cattle. J. Dairy Sci. 91:3888-3895. https://doi.org/ 10.3168/jds.2008-1135.

de Mol, R. M., G. André, E. J. B. Bleumer, J. T. N. van der Werf, Y. de Haas, and C. G. Van Reenen. 2013. Applicability of day-to-day variation in behavior for the automated detection of lameness in dairy cows. J. Dairy Sci. 96:3703-3712. https://doi.org/10.3168/ jds.2012-6305.

Dippel, S., C. B. Tucker, C. Winckler, and D. M. Weary. 2011. Effects of behaviour on the development of claw lesions in early lactation dairy cows. Appl. Anim. Behav. Sci. 134:16-22. https://doi.org/10 .1016/j.applanim.2011.06.006.

Edmonson, A. J., I. J. Lean, L. D. Weaver, T. Farver, and G. Webster. 1989. A body condition scoring chart for Holstein dairy cows. J. Dairy Sci. 72:68-78. https://doi.org/10.3168/jds.S0022 -0302(89)79081-0.

EFSA (European Food Safety Authority). 2009. Scientific report on the effects of farming systems on dairy cow welfare and disease. EFSA J. 7:1143r. https://doi.org/10.2903/j.efsa.2009.1143r.

Espejo, L. A., M. I. Endres, and J. A. Salfer. 2006. Prevalence of lameness in high-producing Holstein cows housed in freestall barns in Minnesota. J. Dairy Sci. 89:3052-3058. https://doi.org/10.3168/ jds.S0022-0302(06)72579-6.

Fregonesi, J. A., and J. D. Leaver. 2002. Influence of space allowance and milk yield level on behaviour, performance and health of dairy cows housed in strawyard and cubicle systems. Livest. Prod. Sci. 78:245-257. https://doi.org/10.1016/S0301-6226(02)00097-0.

González, L. A., B. J. Tolkamp, M. P. Coffey, A. Ferret, and I. Kyriazakis. 2008. Changes in feeding behavior as possible indicators for the automatic monitoring of health disorders in dairy cows. J. Dairy Sci. 91:1017-1028. https://doi.org/10.3168/jds.2007-0530.

Green, L. E., V. J. Hedges, Y. H. Schukken, R. W. Blowey, and A. J. Packington. 2002. The impact of clinical lameness on the milk yield of dairy cows. J. Dairy Sci. 85:2250-2256. https://doi.org/10 .3168/jds.S0022-0302(02)74304-X.

Grimm, K., B. Haidn, M. Erhard, M. Tremblay, and D. Döpfer. 2019. New insights into the association between lameness, behavior, and performance in Simmental cows. J. Dairy Sci. 102:2453-2468. https://doi.org/10.3168/jds.2018-15035.

Henriksen, J. C., and L. Munksgaard. 2019. Validation of AfiTagII, a device for automatic measuring of lying behaviour in Holstein and Jersey cows on two different bedding materials. Animal 13:617621. https://doi.org/10.1017/S1751731118001623.

Holzhauer, M., C. Hardenberg, C. J. M. Bartels, and K. Frankena. 2006. Herd- and cow-level prevalence of digital dermatitis in the Netherlands and associated risk factors. J. Dairy Sci. 89:580-588. https://doi.org/10.3168/jds.S0022-0302(06)72121-X.

Huxley, J. N. 2013. Impact of lameness and claw lesions in cows on health and production. Livest. Sci. 156:64-70. https://doi.org/10 .1016/j.livsci.2013.06.012.

Huzzey, J. M., M. A. G. von Keyserlingk, and D. M. Weary. 2005. Changes in feeding, drinking, and standing behavior of dairy cows during the transition period. J. Dairy Sci. 88:2454-2461. https:// doi.org/10.3168/jds.S0022-0302(05)72923-4.

Ito, K., M. A. G. von Keyserlingk, S. J. LeBlanc, and D. M. Weary. 2010. Lying behavior as an indicator of lameness in dairy cows. J. Dairy Sci. 93:3553-3560. https://doi.org/10.3168/jds.2009-2951.

Jensen, M. B., L. J. Pedersen, and L. Munksgaard. 2005. The effect of reward duration on demand functions for rest in dairy heifers and lying requirements as measured by demand functions. Appl. Anim. Behav. Sci. 90:207-217. https://doi.org/10.1016/j.applanim .2004.08.006.

Kaniyamattam, K., J. Hertl, G. Lhermie, U. Tasch, R. Dyer, and Y. T. Gröhn. 2020. Cost benefit analysis of automatic lameness detection systems in dairy herds: A dynamic programming approach. Prev. Vet. Med. 178:104993. https://doi.org/10.1016/j.prevetmed .2020 .104993 .

Knott, L., J. F. Tarlton, H. Craft, and A. J. F. Webster. 2007. Effects of housing, parturition and diet change on the biochemistry and biomechanics of the support structures of the hoof of dairy heifers. Vet. J. 174:277-287. https://doi.org/10.1016/j.tvjl.2006.09.007.

Leach, K. A., D. N. Logue, S. A. Kempson, J. E. Offer, H. E. Ternent, and J. M. Randalls. 1997. Claw lesions in dairy cattle: Development of sole and white line haemorrhages during the first lactation. Vet. J. 154:215-225. https://doi.org/10.1016/S1090 -0233(97)80024-X.

Leach, K. A., H. R. Whay, C. M. Maggs, Z. E. Barker, E. S. Paul, A. K. Bell, and D. C. J. Main. 2010. Working towards a reduction in cattle lameness: 1 . Understanding barriers to lameness control on dairy farms. Res. Vet. Sci. 89:311-317. https://doi.org/10.1016/j .rvsc. 2010.02.014.

Lim, P. Y., J. N. Huxley, J. A. Willshire, M. J. Green, A. R. Othman, and J. Kaler. 2015. Unravelling the temporal association between lameness and body condition score in dairy cattle using a multistate modelling approach. Prev. Vet. Med. 118:370-377. https:// doi.org/10.1016/j.prevetmed.2014.12.015.

Løvendahl, P., and L. Munksgaard. 2016. An investigation into genetic and phenotypic variation in time budgets and yield of dairy cows. J. Dairy Sci. 99:408-417. https://doi.org/10.3168/jds.2015-9838.

Maselyne, J., M. Pastell, P. T. Thomsen, V. M. Thorup, L. Hänninen, J. Vangeyte, A. Van Nuffel, and L. Munksgaard. 2017. Daily lying time, motion index and step frequency in dairy cows change throughout lactation. Res. Vet. Sci. 110:1-3. https://doi.org/10 $.1016 /$ j.rvsc. 2016.10 .003 .

Munksgaard, L., M. B. Jensen, L. J. Pedersen, S. W. Hansen, and L. Matthews. 2005. Quantifying behavioural priorities - Effects of time constraints on behaviour of dairy cows, Bos taurus. Appl. Anim. Behav. Sci. 92:3-14. https://doi.org/10.1016/j.applanim .2004.11.005.

Munksgaard, L., and H. B. Simonsen. 1996. Behavioral and pituitary adrenal-axis responses of dairy cows to social isolation and deprivation of lying down. J. Anim. Sci. 74:769-778. https://doi.org/10 $.2527 / 1996.744769 x$.

National Research Council. 2001. Nutrient Requirements of Dairy Cattle. 7th rev. ed. Natl. Acad. Press, Washington, DC.

Newsome, R., M. J. Green, N. J. Bell, M. G. G. Chagunda, C. S. Mason, C. S. Rutland, C. J. Sturrock, H. R. Whay, and J. N. Huxley. 2016. Linking bone development on the caudal aspect of the distal phalanx with lameness during life. J. Dairy Sci. 99:4512-4525. https://doi.org/10.3168/jds.2015-10202.

Norring, M., J. Häggman, H. Simojoki, P. Tamminen, C. Winckler, and M. Pastell. 2014. Short communication: Lameness impairs feeding behavior of dairy cows. J. Dairy Sci. 97:4317-4321. https:/ /doi.org/10.3168/jds.2013-7512.

Omontese, B. O., R. Bellet-Elias, A. Molinero, G. D. Catandi, R. Casagrande, Z. Rodriguez, R. S. Bisinotto, and G. Cramer. 2020. Association between hoof lesions and fertility in lactating Jersey cows. J. Dairy Sci. 103:3401-3413. https://doi.org/10.3168/jds .2019-17252.

Proudfoot, K. L., D. M. Weary, and M. A. G. von Keyserlingk. 2010 Behavior during transition differs for cows diagnosed with claw horn lesions in mid lactation. J. Dairy Sci. 93:3970-3978. https:// doi.org/10.3168/jds.2009-2767. 
Schirmann, K., N. Chapinal, D. M. Weary, W. Heuwieser, and M. A. G. von Keyserlingk. 2012. Rumination and its relationship to feeding and lying behavior in Holstein dairy cows. J. Dairy Sci. 95:3212-3217. https://doi.org/10.3168/jds.2011-4741.

Sepúlveda-Varas, P., J. Lomb, M. A. G. von Keyserlingk, R. Held, H. Bustamante, and N. Tadich. 2018. Claw horn lesions in mid-lactation primiparous dairy cows under pasture-based systems: Association with behavioral and metabolic changes around calving. J. Dairy Sci. 101:9439-9450. https://doi.org/10.3168/jds.2018-14674.

Solano, L., H. W. Barkema, E. A. Pajor, S. Mason, S. J. LeBlanc, C. G. R. Nash, D. B. Haley, D. Pellerin, J. Rushen, A. M. de Passille, E. Vasseur, and K. Orsel. 2016. Associations between lying behavior and lameness in Canadian Holstein-Friesian cows housed in freestall barns. J. Dairy Sci. 99:2086-2101. https://doi.org/10 $.3168 /$ jds.2015-10336.

Sprecher, D. J., D. E. Hostetler, and J. B. Kaneene. 1997. A lameness scoring system that uses posture and gait to predict dairy cattle reproductive performance. Theriogenology 47:1179-1187. https:// doi.org/10.1016/S0093-691X(97)00098-8.

Tarlton, J. F., D. E. Holah, K. M. Evans, S. Jones, G. R. Pearson, and A. J. F. Webster. 2002. Biomechanical and histopathological changes in the support structures of bovine hooves around the time of first calving. Vet. J. 163:196-204. https://doi.org/10.1053/tvjl .2001 .0651

Thomsen, P. T. 2009. Rapid screening method for lameness in dairy cows. Vet. Rec. 164:689-690. https://doi.org/10.1136/vr.164.22 689 .

Thomsen, P. T., L. Munksgaard, and J. T. Sørensen. 2012. Locomotion scores and lying behaviour are indicators of hoof lesions in dairy cows. Vet. J. 193:644-647. https://doi.org/10.1016/j.tvjl 2012.06.046.

Thorup, V. M., L. Munksgaard, P. E. Robert, H. W. Erhard, P. T. Thomsen, and N. C. Friggens. 2015. Lameness detection via legmounted accelerometers on dairy cows on four commercial farms. Animal 9:1704-1712. https://doi.org/10.1017/S1751731115000890.

van Amstel, S. R., C. Young, C. Scully, and B. Rohrbach. 2016. Rate of horn growth, wear and sole thickness of dairy cattle in a free stall barn with concrete and rubber flooring. J. Dairy Vet. Anim. Res. 4:305-310. https://doi.org/10.15406/jdvar.2016.04.00120.

Vasseur, E., J. Rushen, D. B. Haley, and A. M. de Passillé. 2012. Sampling cows to assess lying time for on-farm animal welfare assessment. J. Dairy Sci. 95:4968-4977. https://doi.org/10.3168/ jds.2011-5176.

Wang, F. X., D. F. Shao, S. L. Li, Y. J. Wang, A. Azarfar, and Z. J. Cao. 2016. Effects of stocking density on behavior, productivity, and comfort indices of lactating dairy cows. J. Dairy Sci. 99:37093717. https://doi.org/10.3168/jds.2015-10098.

Weary, D. M., J. M. Huzzey, and M. A. G. von Keyserlingk. 2009. Board-invited review: Using behavior to predict and identify ill health in animals. J. Anim. Sci. 87:770-777. https://doi.org/10 $.2527 /$ jas.2008-1297.

\section{ORCIDS}

B. O. Omontese @ https://orcid.org/0000-0001-9341-6483

R. S. Bisinotto @ https://orcid.org/0000-0001-6144-2919

G. Cramer @ https://orcid.org/0000-0003-2691-3417 